\title{
Oral Mucosal Changes in Patients of HIV /AIDS Taking Antiretroviral Therapy in Pakistan
}

\section{Saima Qadir*, Nadia Naseem and A.H. Nagi}

Department of Oral Pathology/ Morbid Anatomy and Histopathology, University of Health Sciences Lahore, Pakistan

"Corresponding author: Saima Qadir, Department of Oral Pathology/ Morbid Anatomy and Histopathology, University of Health Sciences Lahore, Pakistan, Tel: 042-99231304-09; Fax: 042-99230870; E-mail: drsaimaqadir@gmail.com

Rec date: Oct 14, 2014, Acc date: Nov 17, 2014, Pub date: Nov 19, 2014

Copyright: (C) 2014 Qadir S, et al. This is an open-access article distributed under the terms of the Creative Commons Attribution License, which permits unrestricted use, distribution, and reproduction in any medium, provided the original author and source are credited.

\begin{abstract}
Background: This study was designed to describe different oral mucosal changes present in HIVIAIDS patients taking antiretroviral therapy (ART) in Pakistan and to compare these changes with CD4+ lymphocyte count and plasma viral load.

Methods: Oral smears, from $\mathrm{n}=35$ patients taking antiretroviral therapy, were prepared and examined microscopically using routine and special stains. CD4+ lymphocyte count was determined using flow cytometry. Latest plasma viral load levels were recorded from the patient's updated laboratory record and patients were clinically examined and staged according to WHO clinical staging system.
\end{abstract}

Results: Oral lesions were present in $63 \%$ of the patients with oral pigmentation in $45.7 \%$, chronic periodontitis in $20 \%$, linear gingival erythema in $2.9 \%$, pseudomembranous candidiasis, oral ulcers and xerostomia each in $5.7 \%$ cases while mucositis, oral hairy leukoplakia and oral wart each in $2.9 \%$ cases. On cytological examination, fungi were detected in $48.5 \%$ smears. Inflammation was seen in $65.7 \%$ smears, micronuclei in $51.4 \%$, nuclear atypia in $37.1 \%$ and dysplastic changes in $17.1 \%$ (grade 1 in $83.3 \%$ and grade 2 in 17\%) smears. Most of the oral mucosal changes were seen with low CD4+ lymphocyte count but no association was seen with high viral load.

Conclusions: This study describes different oral mucosal changes present in HIVIAIDS patients taking antiretroviral therapy (ART) in Pakistan and highlights their importance as a marker of immunosuppression and disease progression as these changes have strong association with low CD4+ lymphocyte count.

Keywords: Oral lesions; Cytology; CD4+ count; Viral load; Immunosuppression; Disease progression

\section{Introduction}

HIV/AIDS is a growing epidemic in Pakistan. The prevalence in the general population is less than $0.1 \%$ [1]. Oral lesions (OL) in this disease are a basic component of entire disease course and considered as a marker of disease progression and immunosuppression [2]. Oral lesions strongly associated to HIV/AIDS include oral candidiasis, oral hairy leukoplakia, periodontal diseases, oral warts, Kaposi sarcoma and recurrent oral ulcers [3]. There is strong association between oral lesions with decreased CD4+ lymphocyte count and increased viral load [4]. Oral health is the most neglected part of the treatment in HIV/AIDS patients [5]. Antiretroviral therapy (ART) is the most common treatment provided to HIV/AIDS patients. Mostly it consists of two nucleoside reverse transcriptase inhibitors (NRTI) along with one non- nucleoside inhibitor (NNRTI) or one protease inhibitor (PI) [6]. Oral mucosal lesions have been reported to be decreased after ART [2]. Cytology is considered as one of the best non-invasive procedures that can be used to identify variety of cellular changes including dysplastic changes [7]. Relevant data is very scanty that describes the oral mucosal changes that occur during ART in HIV/ AIDS patients in Pakistan and there is no such study reported yet in our country.

\section{Materials and Methods}

The study was approved by the ethical review committee of University of Health Sciences, Pakistan. A total of $n=35$ patients taking Antiretroviral Therapy (ART) were recruited from "The Special HIV/ AIDS Clinic" of Services Institute of Medical Sciences Lahore which is catering the patients from all over Punjab province in Pakistan including high risk areas e.g. Dera Gazi Khan, Jalalpur Jattan, Sargodha, Rahim Yar Khan, Faisalabad etc from the duration of April to September, 2013. It was ensured that all the patients were taking ART comprised of two nucleoside reverse transcriptase inhibitors (NRTI) alongwith one non- nucleoside inhibitor (NNRTI) or one protease inhibitor (PI) at least for 6 months. Patients taking treatment other than this regimen were not included in the study. After taking written informed consent, a complete personal profile, relevant clinical history, findings related to the general physical examination and baseline laboratory investigations of the participant were collected maintaining complete confidentiality of the patients. Patients were clinically staged according to WHO clinical staging system [8]. The oral lesions were diagnosed according to the criteria by Oral HIV/ AIDS Research Alliance (OHARA) [3]. After oral examination, normal saline was given to the patients to rinse the oral cavity and oral smears were prepared by scrapping the buccal mucosa with a wooden spatula and four slides were made from each subject. All the slides were fixed in 95\% ethyl alcohol and then stained with Haematoxylin \& Eosin and Papanicolaou stains by the recommended procedures. 
Periodic Acid Schiff (PAS) and Grocott's Methenamine Silver (GMS) stains were used to confirm the diagnosis of fungi. Blood samples were taken from all patients and CD4+ Cell Count was determined through flow cytometry at the department of Immunology, UHS Lahore, Pakistan. Latest plasma HIV load levels were recorded from the patient's updated laboratory record. Results were analyzed using SPSS 18. Chi-square tests were applied to determine the associations between different variables.

\section{Results}

The mean age of the patients was $40.71 \pm 11.8$ (Range: $24-65)$ years. Most of the patients $(77.1 \%, \mathrm{n}=27)$ were male while $22.9 \%(\mathrm{n}=8)$ were females with male to female ratio of 3.4:1. Majority $(60 \%, n=21)$ of the patients belonged to Lahore followed by Sargodha $(17.14 \%, n=6)$, Dera Ghazi Khan, Buray Walla, Sialkot, Hafizabad and Bhawalpur. About $85.7 \%(n=30)$ subjects were married and $14.3 \%(n=5)$ were unmarried. Family history was present in $2.9 \%(n=1)$ patients with one female having HIV positive husband. History of foreign travelling was present in $14.3 \%(n=5)$ patients. A total of $85.7 \%(n=30)$ patients were in WHO clinical stage $1,5.7 \%(\mathrm{n}=2)$ each in clinical stage 2 and 3 while $2.9 \%(\mathrm{n}=1)$ in clinical stage 4 . Mean duration of the ART was 1.9 years (Range 6 months to 4 years). Out of thirty five patients, $n=8$ were on ART for the last 6 months, $n=3$ for 1 year, $n=18$ were taking antiretroviral therapy for the last 2 years and $n=6$ were on art for 4 years. After careful examination of oral cavity, a total of $63 \%(n=22)$ cases had at least one oral mucosal lesion. Some patients had more than one lesion. Most common lesion was oral mucosal pigmentation (asymmetrical black and brown macules of greater than $1 \mathrm{~cm}$ ) (Figure 1) seen in $45.7 \%(n=16)$ patients. Chronic periodontitis (presence of periodontal pockets $>4 \mathrm{~mm})$ was found in $20 \%(\mathrm{n}=7)$ of cases while one patient $(2.9 \%)$ was found to have linear gingival erythema (red band of about $3 \mathrm{~mm}$ width along the gingival margin). Two cases (5.7\%) of each pseudomembranous candidiasis (scrapable white plaque revealing the erythematous base), oral ulcers (painful mouth sores) and xerostomia (feeling of dry mouth and associated difficulty in deglutition) were observed. One case (2.9\%) of each oral mucositis (mucosal erythema and ulceration with difficulty in deglutition), oral hairy leukoplakia (asymptomatic non-scrapable white corrugated area on the lateral surfaces of tongue) and oral wart (white cauliflower like solitary raised lesion located on the gingiva) were also observed.

On cytological examination, fungi (confirmed by GMS and PAS stains) were detected in $48.5 \%(\mathrm{n}=17)$ smears. Most common fungi were Candida albicans (diagnosed by the presence of Pseudohyphae and yeast cells). Inflammation was observed in $65.7 \%(\mathrm{n}=23)$ smears. Acute inflammation of mild to moderate severity was found in $51.4 \%$ $(\mathrm{n}=18)$ cases with the predominant cell population of neutrophils. In $14.3 \%(n=5)$ of cases, chronic non-specific inflammation of mild severity was seen with predominant cell population of lymphocytes and plasma cells. Micronuclei (round to oval shaped extra nucleus with well-defined membrane, separated from the main nucleus or may overlap it with a diameter of about $1 / 3$ rd of the main nucleus and staining intensity was the same or slightly darker than the main nucleus) were observed in $51.4 \%(\mathrm{n}=18)$ smears. Nuclear atypia showing altered N/C ratio, pleomorphism, increased typical mitosis, prominent nucleoli, karyorrhexis, karyolysis, binucleation and multinucleation was present in $37.1 \%(\mathrm{n}=13)$ of smears. About $17.1 \%$ $(n=6)$ smears showed dysplastic changes with atypical mitosis and/or hyperchromasia. Out of these 6 cases, $83.3 \%$ cases $(n=5)$ were graded as $\mathrm{G1}^{*}$ and $17 \%(\mathrm{n}=1)$ were graded as $\mathrm{G} 2^{*}$ (Figure 2) $\left(\mathrm{G}^{*}\right.$ Mild dysplasia, G2* Moderate dysplasia, G3* severe dysplasia) [9]. No significant association $(p>0.05)$ was seen with age, gender and the duration of ART with the frequency of oral lesions.

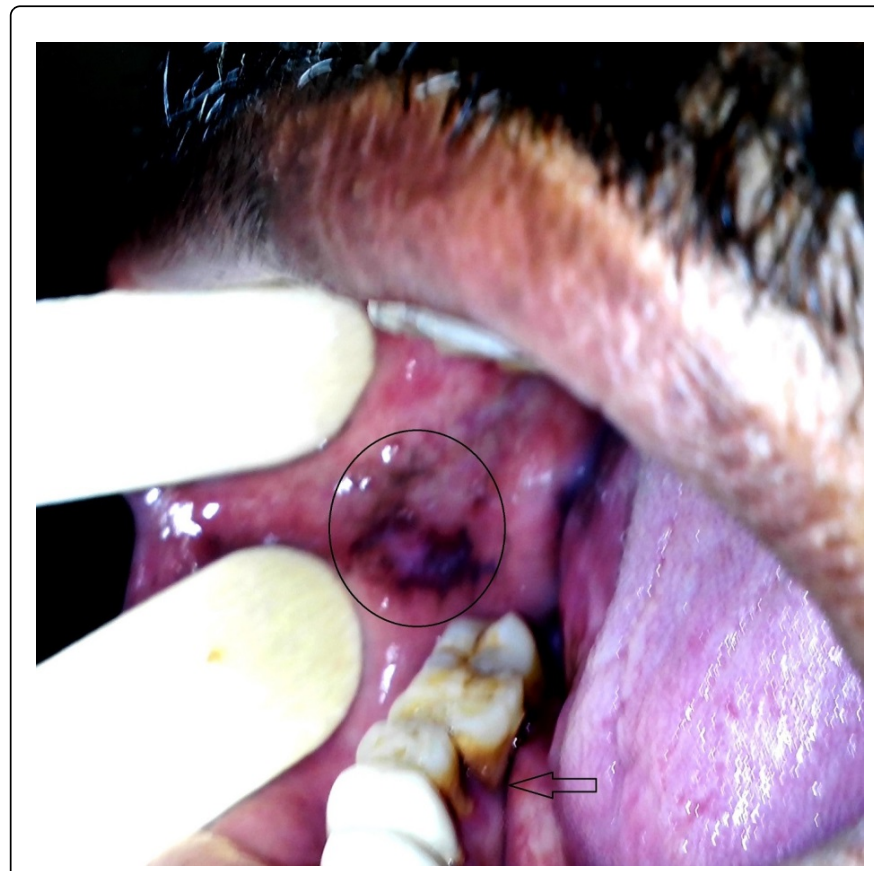

Figure 1: Oral mucosal pigmentation on the buccal mucosa of a 40 years old male. Chronic periodontitis is also evident (arrow).

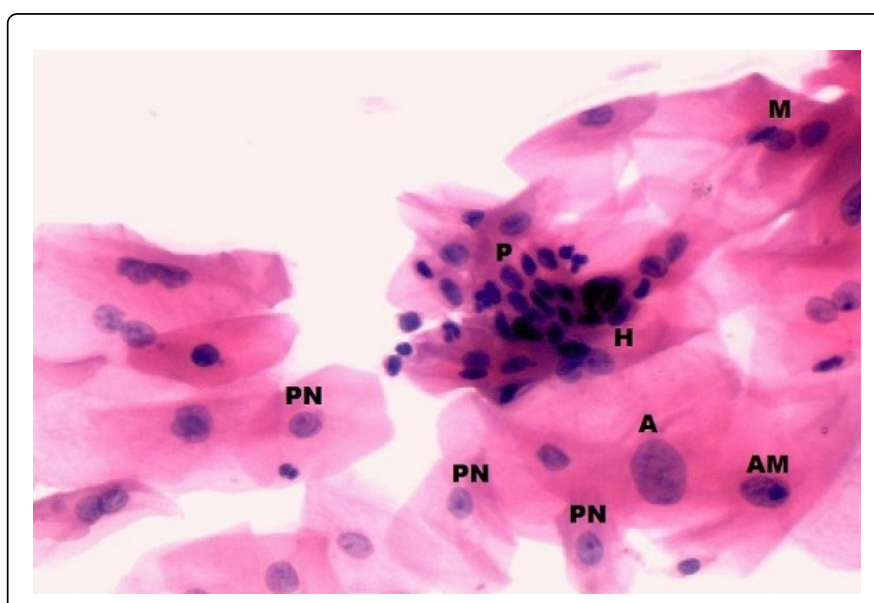

Figure 2: Grade 2 dysplasia of oral squamous cells showing hyper chromasia $(\mathrm{H})$, atypical Mitosis (AM), typical mitosis $(\mathrm{M})$, nuclear pleomorphism (P) and prominent nucleoli (PN) (H\&E) (400X).

Minimum CD4+ lymphocyte count in ART group was 35 cells $/ \mathrm{mm} 3$ and maximum numbers of CD4+ count was 852 cells $/ \mathrm{mm}^{3}$. The mean CD4+ lymphocyte count was $381.20 \pm 214$ cells $/ \mathrm{mm}^{3}$. CD4+ lymphocyte count was quantitatively grouped as $<350$ cells $/ \mathrm{mm}^{3}$ (Group 1) and $>350$ cells $/ \mathrm{mm}^{3}$ (Group 2). This cut point of 350 cells $/ \mathrm{mm}^{3}$ was used for grouping because according to WHO immunological classification, it is the state of advanced immunosuppression [10]. Group 1 comprised of $n=22(63 \%)$ while Group 2 had $n=13(37.1 \%)$ patients. Clinical and cytological variables 
Page 3 of 6

in $\mathrm{n}=35$ patients of ART group were compared to CD4+ lymphocyte count (segregated into Group1 and 2). Applying Chi-square test, the cases showing fungi $(\mathrm{p}=0.001)$ and micronuclei $(\mathrm{p}=0.03)$ were significantly compared with CD4+ lymphocyte count groups. All other variables demonstrated insignificant comparison but most of the clinicocytological changes were seen in CD4+ Group 1 having low CD4+ count (Table 1). Mean viral load was $42025 \pm 150920$ copies $/ \mathrm{mm}^{3}$. Viral load was divided into two groups. Patients in group
1 had viral load of $<3000$ copies $/ \mathrm{mm}^{3}$ while Group 2 had viral load of $>3000$ copies $/ \mathrm{mm}^{3}$. Cut point of 3000 copies $/ \mathrm{mm} 3$ was used for grouping because according to Petruzzi et al. [11], this viral load is a risk factor for the development of oral lesions. Group 1 comprised of $\mathrm{n}=30$ subjects and Group 2 had $\mathrm{n}=5$ patients. No statistically significant association was seen between different clinicocytopathological variables and viral load groups (Table 2).

\begin{tabular}{|c|c|c|c|c|c|}
\hline $\begin{array}{l}\text { Clinicocytological } \\
\text { variables }\end{array}$ & $\begin{array}{l}\text { CD4+Group } 1 \text { (<350 cells } / \mathrm{mm} 3) \\
\mathrm{n}=2263 \%\end{array}$ & $\begin{array}{l}\text { CD4+Group } 2 \text { (>350 cells } / \\
\mathrm{mm} 3) \\
\mathrm{n}=1337 \%\end{array}$ & Total \% & Absent & $P$ value \\
\hline Mucositis & $\mathrm{n}=1(2.9 \%)$ & $\mathrm{n}=0(0 \%)$ & $\mathrm{n}=1(2.9 \%)$ & $\mathrm{n}=34,97 \%)$ & 1.0 \\
\hline Ulcers & $\mathrm{n}=1(2.9 \%)$ & $\mathrm{n}=1(2.9 \%)$ & $n=2(5.7 \%)$ & $\mathrm{n}=3394 \%)$ & 1.0 \\
\hline Oral hairy leukoplakia & $n=1(2.9 \%)$ & $n=0(0 \%)$ & $n=1(2.9 \%)$ & $\mathrm{n}=34(97.1 \%)$ & 1.0 \\
\hline Chronic periodontitis & $n=617 \%)$ & $\mathrm{n}=3(8.6 \%)$ & $n=9(25.7 \%)$ & $\mathrm{n}=26(74.3 \%)$ & 1.0 \\
\hline Oral wart & $n=12.9 \%)$ & $\mathrm{n}=0(0 \%)$ & $n=1(2.9 \%)$ & $\mathrm{n}=34(97.1 \%)$ & 1.0 \\
\hline Pigmentation & $n=16(45.7 \%)$ & $\mathrm{n}=6(17.1 \%)$ & $n=22(62.9 \%)$ & $\mathrm{n}=13(37.1 \%)$ & 0.1 \\
\hline Pseudomembranous candidiasis & $n=2(5.7 \%)$ & $\mathrm{n}=0(0 \%)$ & $n=25.7 \%)$ & $\mathrm{n}=33(94.3 \%)$ & 0.5 \\
\hline Inflammation & $n=13(37.1 \%)$ & $n=10(28.6 \%)$ & $n=23(65.7 \%)$ & $\mathrm{n}=12(34.3 \%)$ & 0.4 \\
\hline Dysplasia & $n=5(14.3 \%)$ & $n=1(2.9 \%)$ & $n=6(17.1 \%)$ & $\mathrm{n}=29(82.9 \%)$ & 0.3 \\
\hline Fungi & $n=16(45.7 \%)$ & $n=1(2.8 \%)$ & $n=17(48.5 \%)$ & $\mathrm{n}=18(51.5 \%)$ & 0.001 \\
\hline Micronuclei & $n=15(42.9 \%)$ & $\mathrm{n}=4(11.4 \%)$ & $n=1954 \%)$ & $\mathrm{n}=16(45.7 \%)$ & 0.03 \\
\hline Nuclear Atypia & $\mathrm{n}=11(31.4 \%)$ & $n=25.7 \%)$ & $n=1337 \%)$ & $n=2263 \%)$ & 0.07 \\
\hline
\end{tabular}

Comparison of clinical and cytological variables in $n=35$ patients with CD4+ lymphocyte count. Note only the presence of fungi $(p=001)$ and micronuclei $(p=0.03)$ showed significant associations (Chi-square tests).

Table 1: Comparison of Clinicocytological Variables with CD4+ Lymphocyte Count Groups in patients on ART.

\section{Discussion}

The mean age of the patients in the present study was $40.71 \pm 11.8$ (Range: 24-65) years. This range (24-65) finding corresponds with the fact that sexually active age group is more prone to acquire HIV infection. Mir et al. [12] and Mathur [13] from India had the same observation.

Most of the patients $(77.1 \%, n=27)$ were male while $22.9 \%(n=8)$ were females with male to female ratio of 3.4:1. This finding signifies that HIV/AIDS is more commonly reported in males than females in Pakistan as compliant with the other studies from Pakistan [14]. About $85.7 \%(n=30)$ subjects were married and $14.3 \%(n=5)$ were unmarried in this study. Khan and Khan [15] reported that about half of injecting drug users (IDUs) and sex workers are married and $20 \%$ of them are infected with HIV in Pakistan. Family history was present in $2.9 \%(n=1)$ patients with one female having HIV positive husband. History of foreign travelling was present in $14.3 \%(n=5)$ patients. Spread of HIV infection from HIV positive husbands to their wives especially in migrant workers is also an important dilemma in Pakistan reported by Khanani et al. [15,16]. Majority $(60 \%, n=21)$ of the patients belonged to Lahore followed by Sargodha $(17.14 \%, n=6)$, Dera Ghazi Khan, Buray Walla, Dera Gazi khan, Sialkot, Hafizabad and Bhawalpur which are the high risk areas in Pakistan [15].
Oral lesions were found in $63 \%(n=22)$ of the patients in this study but Ceballos-Salobreña et al. [17] had reported a lower frequency of oral lesions (up to 53\%) than the present study in patients on ART. Higher frequency of oral lesions in the present study may be due to the fact that most patients in this study $(\mathrm{n}=22)$ had CD4+lymphocyte count $<350$ cells $/ \mathrm{mm} 3$ which is considered as the state of advanced immunosuppression according to WHO immunological classification system [10]. On clinical examination, chronic periodontitis was seen in $20 \%(n=7)$ cases with one patient $(2.9 \%)$ having linear gingival erythema (minor form of necrotizing periodontitis). Rath \& Raj (2013) [18] have reported the periodontitis in 29\% HIV/AIDS patients on ART which is higher than the present study. In the present study, oral mucosal pigmentation was observed in $45.7 \%(n=16)$ of the cases. Adverse effects of ART can lead to oral mucosal hyperpigmentation as reported by Umadevi et al. [2] from India. Nittayananta et al. [19] found the mucosal hyperpigmentation in $46 \%$ patients which is in compliant with the result of present study. Pseudomembranous candidiasis was found in $5.7 \%(\mathrm{n}=2)$ patients in this study. It is included in group 1 lesions strongly associated to HIV/AIDS according to Oral HIV/ AIDS Research Alliance (OHARA) [3]. Lourenço et al. [20] reported the frequency of pseudomembranous candidiasis in $9.3 \%$ HIV/AIDS patients in ART era which is higher than the present study. Association of oral candidiasis with increased viral load and decreased CD4+ count is well documented so it can be considered a clinical marker of severe immune deficiency, the disease 
progression and presence of opportunistic infections [21]. Oral ulcers were found in $5.7 \%(\mathrm{n}=2)$ patients on ART in this study which is incompliant with the study of Jindwani et al. [22]. Oral ulcers are included in less commonly associated lesions in HIV/AIDS patients by
OHARA classification [3]. Arirachakaran from Thailand [23] attributed the presence of oral ulcers in HIV positive patients to ART especially NRTI.

\begin{tabular}{|l|l|l|l|l|l|}
\hline \multicolumn{2}{|l|}{ Present } & Absent & P value \\
\hline Clinicocytological variables & Group 1 & Group 2 & Total \%) & & \\
\hline Mucositis & $\mathrm{n}=1(2.9 \%)$ & $\mathrm{n}=0(0 \%)$ & $\mathrm{n}=1(2.9 \%)$ & $\mathrm{n}=34(97 \%)$ & 0.56 \\
\hline Oral ulcers & $\mathrm{n}=2(5.7 \%)$ & $\mathrm{n}=0(0 \%)$ & $\mathrm{n}=2(5.7 \%)$ & $\mathrm{n}=33(94.3 \%)$ & 1 \\
\hline Oral hairy leukoplakia & $\mathrm{n}=1(2.9 \%)$ & $\mathrm{n}=0(0 \%)$ & $\mathrm{n}=1(2.9 \%)$ & $\mathrm{n}=34(97.1 \%)$ & 1 \\
\hline Chronic periodontitis & $\mathrm{n}=9(25.7 \%)$ & $\mathrm{n}=0(0 \%)$ & $\mathrm{n}=9(25.7 \%)$ & $\mathrm{n}=26(74.3 \%)$ & 0.3 \\
\hline Oral wart & $\mathrm{n}=1(2.9 \%)$ & $\mathrm{n}=0(0 \%)$ & $\mathrm{n}=1(2.9 \%)$ & $\mathrm{n}=34(97.1 \%)$ & 1 \\
\hline Oral pigmentation & $\mathrm{n}=20(57.1 \%)$ & $\mathrm{n}=2(5.7 \%)$ & $\mathrm{n}=22(62.9 \%)$ & $\mathrm{n}=1337.14 \%)$ & 0.34 \\
\hline Pseudomembranous Candidiasis & $\mathrm{n}=1(2.9 \%)$ & $\mathrm{n}=1(2.9 \%)$ & $\mathrm{n}=2(5.7 \%)$ & $\mathrm{n}=33(94.3 \%)$ & 0.27 \\
\hline Inflammation & $\mathrm{n}=2160 \%)$ & $\mathrm{n}=2(5.7 \%)$ & $\mathrm{n}=23(65.7 \%)$ & $\mathrm{n}=12(34.3 \%)$ & 0.31 \\
\hline Dysplasia & $\mathrm{n}=6(17.1 \%)$ & $\mathrm{n}=0(0 \%)$ & $\mathrm{n}=6(17.1 \%)$ & $\mathrm{n}=29(82.9 \%)$ & 0.56 \\
\hline Fungi & $\mathrm{n}=16(45.7 \%)$ & $\mathrm{n}=1(2.8 \%)$ & $\mathrm{n}=17(48.5 \%)$ & $\mathrm{n}=18(51.5 \%)$ & 0.82 \\
\hline Micronuclei & $\mathrm{n}=16(45.7 \%)$ & $\mathrm{n}=3(8.6 \%)$ & $\mathrm{n}=19(54.3 \%)$ & $\mathrm{n}=16(45.7 \%)$ & 1 \\
\hline Nuclear Atypia & $\mathrm{n}=13(37.1 \%)$ & $\mathrm{n}=0(0 \%)$ & $\mathrm{n}=13(37.1 \%)$ & $\mathrm{n}=22(62.9 \%)$ & 0.13 \\
\hline $\begin{array}{l}\text { Association between different clinicopathological variables and viral load groups in } \mathrm{n}=35 \text { patients. (Chi-square tests). Note no significant association (p>0.05) was seen } \\
\text { between clinicopathological variables and viral load group. }\end{array}$ & & \\
\hline
\end{tabular}

Table 2: Comparison of clinicocytological variables with viral load groups in patients on ART.

Oral hairy leukoplakia (OHL) is included in group 1 oral lesions which are strongly associated to HIV/AIDS according to OHARA classification [3]. It was observed in $2.9 \%(\mathrm{n}=1)$ patients in the present study. Ranganathan et al. [24] also reported one case (0.33\%) of OHL.

Mucositis and oral wart were seen each with $2.9 \%(n=1)$ frequency in the present study. Arirachakaran. [22] attributed the mucositis to the adverse effect of ART in HIV positive patients. Two cases (5.7\%) of xerostomia were also observed in the present study. Frequency of oral wart and xerostomia is reported to be increased after ART by Reznik [25]. Differences and similarities in the prevalence of HIV-associated oral lesions vary according to variable sample size, degree of immunosuppression, inter-examiner differences but the patterns of the oral lesions are nearly the same [26].

No study has been reported in the literature which describes the frequency of different cytological changes in the oral squamous cells of HIV/AIDS patients. On cytological examination, most common observation was the presence of micronuclei, present in $51.4 \%(\mathrm{n}=18)$ of the smears. Shimura et al. [27] reported that Vpr an accessory gene of HIV may be involved in micronucleation while Casartelli et al. [28] reported that gradual increase in micronucleus counts from normal mucosa to precancerous lesions to carcinomas suggests a link of this biomarker with neoplastic progression. Inflammation was present in $65.7 \%(n=23)$ smears. Inflammation of oral cavity is a cardinal lesion in HIV/AIDS patients due to decreased immunity. HIV infection leads to long-term immune activation and chronic inflammation [29].

As regards the histochemistry, on PAS and GMS stains, fungi were detected in $48.5 \%(\mathrm{n}=17)$ of smears. Candida albicans was the commonest $(53 \%, \mathrm{n}=9)$. Oral Candidiasis is a very common observation in HIV/AIDS patients in many studies reported in the literature [30,31]. It is an early manifestation of HIV that can occur in patients who appear otherwise healthy.

Nuclear atypia was found in $37.1 \%(n=13)$ cases. Dysplasia with atypical mitosis and hyperchromasia was found in $17.1 \%(n=6)$ cases. Nuclear atypia and dysplastic changes in HIV/AIDS patients may suggest that HIV/AIDS patients are at increased risk of developing oral cancers [32]. Carlos et al. [33] reported that abnormal cytological changes including nuclear atypia and dysplasia are mostly seen with low CD4+ lymphocyte count especially less than 200 cells $/ \mathrm{mm}^{3}$.

Comparison of CD4+lymphocyte count groups with clinical and cytological variables yielded significant association $(p<0.05)$ in case of fungi and micronuclei. Although all other variables yielded insignificant association but most of the lesions were seen in Group1 patients with CD4+lympocyte count $<350 \mathrm{cells} / \mathrm{mm}^{3}$ as compared to Group 2 patients with higher CD4+lympocyte count ( $>350$ cells/ $\mathrm{mm}^{3}$ ). The above results describe that frequency of oral lesions are more common with decreasing CD4+ lymphocyte count as compliant with the study by Mathur [4].

No statistically significant association $(\mathrm{p}>0.05)$ was seen between clinicocytopathological variables and viral load groups. However Reznik [25] from Georgia have reported that levels of plasma HIV RNA greater than 3000 copies $/ \mathrm{ml}$ may be the predisposing factors in the development of oral mucosal lesions. There was no increase in the CD4+ count with the decrease in the viral load. This can be attributed to the small study population. However Smith et al. [34] from London 
reported increase in CD4+ lymphocyte count with decrease in viral load after ART.

No such study has ever been reported from Pakistan so the findings of this research project may prove to be helpful in prevention as well as management of oral lesions ranging from simple inflammation to dysplasia/pre malignant oral lesions in HIV/AIDS patients in Pakistan. The data complies well with the documented reports from the world where such study from Pakistan may also add to the previous literature.

\section{Conclusion}

Oral mucosal lesions are frequent in HIV/AIDS patients with low CD4+lymphocyte count $\left(<350\right.$ cells $\left./ \mathrm{mm}^{3}\right)$. Different types of the oral lesions were found in patients on ART including mucositis, oral ulcers, oral hairy leukoplakia, pseudomembranous candidiasis, oral hyperpigmentation, chronic periodontitis and oral wart. A variety of cytopathological changes including inflammation, presence of fungi, nuclear atypia, micronuclei and dysplasia were also observed in these patients. In resource constrained countries like Pakistan, where repeated CD4+ lymphocyte count and viral load testing is expensive for the majority of HIV/AIDS patients belonging to low socioeconomic status, oral mucosal changes can be used as a noninvasive marker for the prediction of immunosuppression and ART failure

\section{Acknowledgement}

Authors acknowledge Punjab AIDS Control Programme Pakistan and Department of immunology, University of Health Sciences Pakistan for their technical and logistic support.

\section{References}

1. Khan MS, Unemo M, Zaman S, Lundborg CS (2011) HIV, STI prevalence and risk behaviours among women selling sex in Lahore, Pakistan. BMC Infect Dis 11: 119.

2. Umadevi KM, Ranganathan K, Pavithra S, Hemalatha R, Saraswathi TR, et al. (2007) Oral lesions among persons with HIV disease with and without highly active antiretroviral therapy in southern India. J Oral Pathol Med 36: 136-141.

3. Shiboski CH, Patton LL, Webster-Cyriaque JY, Greenspan D, Traboulsi RS, et al. (2009) The Oral HIV/AIDS Research Alliance: updated case definitions of oral disease endpoints. J Oral Pathol Med 38: 481-488.

4. Mathur N (2013) Correlation between Oral Manifestations and CD4+ count of HIV+ve patients. J Evolution Med Dent Sci 12: 4419-4424.

5. Saddki N, Majdiah W, Mohamad W (2011) Oral Health-Related Quality of Life Among People Living with HIV/AIDS. Chapter 7 IN [HIVinfection - Impact, Awareness and Social Implications of living with HIV/AIDS].

6. World Health Organization (WHO), (2013) Consolidated guidelines on the use of antiretroviral drugs for treating and preventing HIV infection: summary of key features and recommendations.

7. Dolens Eda S, Nakai FV, Santos Parizi JL, Alborghetti Nai G (2013) Cytopathology: a useful technique for diagnosing oral lesions?: a systematic literature review. Diagn Cytopathol 41: 505-514.

8. World Health Organization(WHO), (2007) WHO Case Definitions of HIV for Surveillance and Revised Clinical Staging and Immunological Classification of HIV-Related Disease in Adults and Children. 2007.

9. Speight PM (2007) Update on oral epithelial dysplasia and progression to cancer. Head Neck Pathol 1: 61-66.
10. Hegde, MN, Hegde ND, Malhotra A, (2012) Prevalence of oral lesions in HIV infected adult population of Mangalore, Karnataka, India. BioDiscovery 4:3.

11. Petruzzi MN, Cherubini K, Salum FG, Figueiredo MA (2013) Risk factors of HIV-related oral lesions in adults. Rev Saude Publica 47: 52-59.

12. Mir MA, Peer Maroof Ahmad, Mushtaq Ahmad Siddeque, Fayaz Ahmad Sofi, Syed Nisar Ahmad, et al. (2010) Clinical and demographic profile of HIV/AIDS patients diagnosed at a tertiary care centre in Kashmir. JPMA, 60: 428.

13. Mathur N, (2013) Correlation between Oral Manifestations and CD4+ count of HIV+ve patients. J Evolu of Med and Dent Sc 12: 4419-4424.

14. Bhurgi Y, (2006) HIV/AIDS in Pakistan. J Pak Med Assoc 56: 3-4.

15. Khan AA, Khan A (2010) The HIV epidemic in Pakistan. J Pak Med Assoc 60: 300-307.

16. Khanani MR, Somani M, Rehmani SS, Veras NM, Salemi M, et al. (2011) The spread of HIV in Pakistan: bridging of the epidemic between populations. PLoS One 6: e22449.

17. Ceballos-Salobreña A, Gaitán-Cepeda LA, Ceballos-Garcia L, LezamaDel Valle D (2001) Oral lesions in HIV/AIDS patients undergoing highly active antiretroviral treatment including protease inhibitors: a new face of oral AIDS? AIDS Patient Care STDS 14: 627-635.

18. Rath H, Raj SC (2013) Assessment of oral health status and Treatment needs of HIV/AIDS patients visiting Government Hospitals and Rehabilitation centers in Banglore city. Indian J Sex Transm Dis 34: $59-60$.

19. Nittayananta W, Talungchit S, Jaruratanasirikul S, Silpapojakul K, Chayakul P, et al. (2010) Effects of long-term use of HAART on oral health status of HIV-infected subjects. J Oral Pathol Med 39: 397-406.

20. Lourenço AG, Motta AC, Figueiredo LT, Machado AA, Komesu MC (2011) Oral lesions associated with HIV infection before and during the antiretroviral therapy era in Ribeirão Preto, Brazil. J Oral Sci 53: 379-385.

21. Bravo IM, Correnti M, Escalona L, Perrone M, Brito A, et al. (2006) Prevalence of oral lesions in HIV patients related to CD4 cell count and viral load in a Venezuelan population. Med Oral Patol Oral Cir Bucal 11: E33-39.

22. Jindwani K, Singh K, Dadlani H (2013) A study of oral lesions among H.I.V positives in a tertiary care hospital. Biomed Res 24: 40-42.

23. Arirachakaran P (2009) Highly active antiretroviral therapy and its oral manifestations in HIV patients. CU Dent J 32: 69-88.

24. Ranganathan K, Reddy BV, Kumarasamy N, Solomon S, Viswanathan R, et al. (2000) Oral lesions and conditions associated with human immunodeficiency virus infection in 300 south Indian patients. Oral Dis 6: 152-157.

25. Reznik DA (2005) Oral manifestations of HIV disease. Top HIV Med 13: 143-148.

26. Patton LL, Phelan JA, Ramos-Gomez FJ, Nittayananta W, Shiboski CH, et al. (2002) Prevalence and classification of HIV-associated oral lesions. Oral Dis 8 Suppl 2: 98-109.

27. Shimura M, Tanaka Y, Nakamura S, Minemoto Y, Yamashita K, et al. (1999) Micronuclei formation and aneuploidy induced by Vpr, an accessory gene of human immunodeficiency virus type 1. FASEB J 13: 621-637.

28. Casartelli G, Bonatti S, De Ferrari M, Scala M, Mereu P, et al. (2000) Micronucleus frequencies in exfoliated buccal cells in normal mucosa, precancerous lesions and squamous cell carcinoma. Anal Quant Cytol Histol, 22: 486-492.

29. Highleyman L (2010) Inflammation, immune activation, and HIV. BETA 22: $12-26$

30. Ranganathan K, Hemalatha R (2006) Oral lesions in HIV infection in developing countries: an overview. Adv Dent Res 19: 63-68.

31. Grover HS, Bhardwaj A, Gupta H (2013) Oral cavity: A mirror to HIV manifestations. Int J Pharm 4:13-18.

32. Shiels MS, Cole SR, Kirk GD, Poole C (2009) A meta-analysis of the incidence of non-AIDS cancers in HIV-infected individuals. J Acquir Immune Defic Syndr 52: 611-622. 
Citation: Qadir S, Naseem N, Nagi AH (2014) Oral Mucosal Changes in Patients of HIV IAIDS Taking Antiretroviral Therapy in Pakistan. J Cytol Histol S4: 019. doi:10.4172/2157-7099.S4-019

Page 6 of 6

33. Pineda CE, Welton ML (2009) Management of anal squamous intraepithelial lesions. Clin Colon Rectal Surg 22: 94-101.

34. Smith CJ, Sabin CA, Youle MS, Loes KS, Lampe FC, et al. (2004) Factors Influencing Increases in CD4 Cell Counts of HIV-Positive Persons
Receiving Long-Term Highly Active Antiretroviral Therapy. J Infect Dis 190: $1860-1868$.

This article was originally published in a special issue, entitled: "Histology and Histopathology", Edited by Borislav A. Alexiev, University of Maryland Medical Center, USA 